\title{
ELLJ
}

\section{Discrimination within a group of workers with disabilities. Comment to Court of Justice of the European union, case C-16/19}

European Labour Law Journal 2022, Vol. I3(I) I27-134 (C) The Author(s) 2021 Article reuse guidelines: sagepub.com/journals-permissions DOI: $10.1177 / 20319525211066119$ journals.sagepub.com/home/ell

@SAGE

\section{Pedro Oliveira}

University of Coimbra, Portugal

University of California, Berkeley

Portuguese Foundation for Science and Technology

\begin{abstract}
In January 202I, the Court of Justice of the European Union delivered a remarkable judgment regarding the rights of workers with disabilities. The case concerned a Polish employer who decided to grant a monthly allowance to workers with disabilities if such workers provided a disability certificate after a certain date. However, those workers who had submitted their certificates before the specified date, including VL, were not entitled to that allowance. As a result, VL brought an action against the employer before a Polish Court claiming that she had been discriminated against due to her disability. The aim of the following note is to raise awareness regarding some of the main points of the argumentative rhetoric of the Court of Justice.
\end{abstract}

\section{Keywords}

Equality Framework Directive, direct discrimination, indirect discrimination, disability, workers with disabilities

\section{Corresponding author:}

Pedro Oliveira, University of Coimbra, Portugal; University of California, Berkeley; Portuguese Foundation for Science and Technology.

E-mail: pedrooliveira@berkeley.edu 


\section{Introduction}

In a recent ruling, ${ }^{1}$ the Court of Justice of the European Union (CJEU) was once more called upon to speak on matters of interpretation within the context of the Equality Framework Directive, which establishes a general framework for equal treatment in employment and occupation. ${ }^{2}$

The case concerned two essential matters. The first was the familiar (and not always unequivocal) definition of direct and indirect discrimination, laid down in Article 2(2)(a) and (b) of the said normative document. ${ }^{3}$ The other, however, was new to the European Union's judicature, as Advocate General Giovanni Pitruzzella pointed out as he began his conclusions: 'the legal question at the root of the present proceeding, unprecedented for the Court of Justice, is the applicability of discriminatory actions (direct or indirect) regarding an employer's behaviour whose treatment towards two groups of people [with disabilities] is different'.

In effect, the Luxemburg areopagus had never before decided on a case in which the interests of a disabled worker against other workers with disabilities were in question. The aim of the following note is to raise awareness regarding some of the main points of the argumentative rhetoric of the Court of Justice in one more important counter on its board game.

\section{The Dispute}

VL was employed as a psychologist by the Dr. J. Babiński Hospital from 3 October 2011 to 30 September 2016. On 8 December 2011, she obtained a disability certificate, which she submitted to her employer on 21 December 2011.

In 2013, following a meeting with the staff, the director of the hospital decided to grant a monthly allowance to workers submitting disability certificates after that meeting. The measure was intended to reduce the amount of the contributions payable by the hospital to the State Fund for the Rehabilitation of Persons with Disabilities. The relevant date for the granting of the allowance was not the date on which the disability certificate was obtained, but the date of its submission to the director.

The allowance was granted individually to 13 workers who had submitted their disability certificates after that meeting. By contrast, 16 workers who had submitted their certificates to the employer before that meeting, including VL, did not receive the allowance.

As a result, VL brought an action against her employer before the Sad Rejonowy dla KrakowaNowej Huty w Krakowie IV Wydzial Pracy i Ubezpieczeń Społecznych (District Court for Kraków-Nowa Huta in Kraków, 4th Labour and Social Insurance Division, Poland), arguing that she had been the subject of discrimination with regard to pay.

The court dismissed her action, and VL lodged an appeal with the referring court, the Sad Okregowy w Krakowie (Regional Court, Kraków, Poland).

1 CJEU Case C-16/19 VL v Szpital Kliniczny im. Dra J. Babinskiego Samodzielny Publiczny Zaklad Opieki Zdrowotnej w Krakowie [2021] ECLI: C:2021: 64. See, also, the Opinion of Advocate General Pitruzella of 18.06.2020, ECLI:EU: C:2020:479.

2 Council Directive 2000/78/EC of 27 November 2000 establishing a general framework for equal treatment in employment and occupation OJ 2000 L 303, 16.

3 The Advocate General Giovanni Pitruzzella emphasises: 'the distinction between direct discrimination and indirect discrimination is not particularly clear from the wording of the directive, and there are differing opinions also in the interpretation of those two categories'. See Case $V$ L, Opinion of $A G$ Pitruzzella, para 74.

4 Case $V L$, Opinion of AG Pitruzzella, para 3. 
In her appeal, VL argued that her employer granted the allowance to a group of workers sharing a common characteristic, namely a disability, but on the condition that they submitted their disability certificates after a date chosen by the employer, which had the effect of excluding workers who had submitted their certificates before that date from receiving that allowance. VL considered that such a practice, the aim of which was to encourage workers with disabilities who had not yet submitted disability certificates to do so, in order to reduce the amount of the contributions payable by the hospital to the State Fund for the Rehabilitation of Persons with Disabilities, was contrary to Directive 2000/78, which prohibits all discrimination, whether direct or indirect, on grounds of disability.

In that regard, the referring court questioned whether indirect discrimination within the meaning of Article 2 of Directive 2000/78 may be taken to occur where a distinction is made by an employer within a group of workers defined by a protected characteristic - in this instance, disability without the workers with disabilities in question being treated less favourably than workers who do not have disabilities.

In those circumstances, the Sąd Okregowy w Krakowie (Regional Court, Kraków) decided to stay the proceedings and to refer the following question to the Court of Justice for a preliminary ruling:

Should Article 2 of [Directive 2000/78] be interpreted as meaning that the differing treatment of individual members of a group distinguished by a protected characteristic (disability) amounts to a breach of the principle of equal treatment if the employer treats individual members of that group differently on the basis of an apparently neutral criterion, that criterion cannot be objectively justified by a legitimate aim, and the measures taken in order to achieve that aim are not appropriate and necessary?

\section{Issues at stake}

As can be inferred from the circumstances briefly described above, one of the fundamental points discussed by the national judicature was regarding the scope and reach of the discrimination definition for the purposes of the Polish framework that transposed Directive 2000/78.

The arguments presented in the litigation provide two main interpretations. The worker, VL, believed that her situation could fall under the remit of Directive 2000/78. As she later acknowledged, the Court of First Instance ruled against her. It held that VL had not been discriminated against due to her disability as such treatment would imply that there had been a distinction made between disabled workers and those with no disability. On the other hand, the distinctive criterion adopted by the hospital was the date on which the document attesting to the disability had been delivered, and not the fact that VL had a disability.

The Court of Appeal, more hesitant (or more cautious), did not dismiss the matter and referred a question to the Court of Justice regarding the possible use of the discrimination definition in a case where the difference in treatment takes place within a group of workers that is defined by the same protective characteristic (the disability), and also with regard to how the conduct of the hospital would be qualified under indirect discrimination law.

\section{Directive $2000 / 78$}

Firstly, some of the normative elements considered in the VL case should be noted, in particular, Directive 2000/78. As we are aware, the scope of this Directive is to promote the general principle 
of equality within the European Union by combating discrimination on the grounds of disability, religion or belief, age or sexual orientation. ${ }^{5}$ Contrary to the recommendations contained in the Directive, as a harmonising instrument that allows for changes to its rules in melius, ${ }^{6}$ the Court of Justice has ruled that such list of grounds is exhaustive. Also, and contrary to what happens in other fields, e.g. ethnic discrimination, its material scope is circumscribed by the specific context of labour relations.

Of utmost importance within the legal framework of Directive 2000/78, Article 2 (1) defines the principle of equal treatment as the lack of any discrimination, whether direct or indirect, for any of the aforementioned grounds, which include disability. ${ }^{7}$ On the other hand, points (a) and (b) of Article 2 (2) of the same Directive regulate the two types of discrimination, which, as previously discussed, are not always easily defined.

According to Mariana Canotilho, the fundamental element that sets them apart is in the more or less evident, or visible, character of the discrimination' ${ }^{8}$ In effect, so-called direct discriminatory conduct occurs when, because of their disability, one person is treated less favourably than another is, has been, or would be, treated in a comparable situation. We are talking about 'ostentatious, expressive discrimination', 9 the grounds of which must be explicitly shown in order to be determined. The comparability test applies, and therefore, the term of comparison is an essential element in reaching a decision on the case.

In turn, indirect discrimination occurs where an apparently neutral provision, criterion or practice would put a person - namely, someone with a particular disability - at a particular disadvantage when compared with other persons. This type of discrimination consists of 'measures which, on a strictly formal level, are indistinctly applicable with regard to the differentiation criteria forbidden by the legal framework but which, on a practical and material level, have an effect similar to that of direct discrimination'. ${ }^{10}$

However, it is worth noting that contrary to what happens in the case of direct discrimination, indirect discrimination can be objectively justified. The following requirements (a general one, and a more specific one) infer the existence of indirect discrimination: elements that show that the provision, criterion or practice place the worker with one of the protected characteristics in a disadvantageous position; and that such provision, criterion or practice cannot be objectively justified. ${ }^{11}$

5 Directive 2000/78, Article 1.

6 See Mark Bell \& Ann Numhauser-Henning, 'Equal Treatment', in Teun Jaspers, Frans Pennings, and Saskia Peters (eds.), European Labour Law, Cambridge, Intersentia, 2019, 153.

7 In contrast to what occurred, for instance, in the framework of gender norms, the EU acquired the legislative competence on disability solely after the adoption of the Amsterdam Treaty (Article 122 - now Article 19 of the Treaty on the Functioning of the European Union). The provision constitutes the legal basis of Directive 2000/78. For an in-depth analysis on the evolution of the competence of the EU on disability law, see Lisa Waddington, 'The European Union and the United Nations Convention on the Rights of Persons with Disabilities: A story of exclusive and shared competences', Maastricht Journal of European and Comparative Law 2011, vol. 18, 431-453.

8 Mariana Canotilho, 'Igualdade de Oportunidades e Não Discriminação', in Direito da União Europeia - Elementos de Direito e Políticas da União, Coimbra, Almedina, 2016, 891.

9 Ibid, 891. According to M. Bell \& A. Numhauser-Henning (n 6), 155, 'the strength of the concept of direct discrimination lies in the absence of any possibility to justify such conduct'.

10 Mariana Canotilho (n 8), p. 892.

11 In accordance with Article 2 (2)(b) of Directive 2000/78, unless (i) that provision, criterion or practice is objectively justified by a legitimate aim and the means of achieving that aim are appropriate and necessary, or (ii) as regards persons with a particular disability, the employer or any person or organisation to whom this Directive applies, is obliged, under national legislation, to take appropriate measures in line with the principles contained in Article 5 in order to eliminate disadvantages entailed by such provision, criterion or practice. 
The simplicity of these norms hides many sensitive problems. To start with, these problems arise from the compartmentalisation issues in terms of direct and indirect discrimination, as well as doubts regarding the term of comparison, as it is not always easy to understand when the Court of Justice perceives two situations as being comparable. Indeed, the ruling discussed reflects another example of the problems encountered with regard to this matter.

\section{Comparability Criterion}

It was important that, first of all, the Court of Justice determined whether or not the manner in which the worker, VL, claimed to be treated differently would fall within the scope of Directive 2000/78. It should be reiterated that the innovative element of the EU's jurisprudence is in seeking to understanding whether such desideratum does indeed comprise discrimination between workers with the same protected characteristic, in casu, disability.

To date, in most cases before the Court, interpretation involved the use of the comparability test between the situation of a worker with a certain distinctive quality and another who did not have such a quality. The reasoning was simple and logical. A worker complaining of having been discriminated against by their employer due to disability would have their situation assessed in comparison to that of a worker with no disability. The same would be the case with regard to other grounds of discrimination specifically laid down in the Directive. ${ }^{12}$

In the end, the complexity of what is real would somehow mitigate the dominant logic in the EU's equality and non-discrimination law, in particular, with regard to choosing a comparator. In effect, not only are there cases in which it is not very clear, there are also other cases where less focus seems to be placed on such comparators. ${ }^{13}$

It is not surprising that in the case in question, the positions adopted regarding such a nodal point did not coincide. On one side, there was the hospital and the European Commission, who, by restrictively interpreting the enforcement scope of the Directive, asserted that it was limited to the discriminatory treatment of workers with a disability compared to workers with no disability. On the other hand, the worker and the Polish and Portuguese governments were of the opinion that that the Directive would be equally applicable to a situation "where the different treatment was limited to the category of workers with disability, and also that the differentiating element would not be directly connected to it'. ${ }^{14}$

As mentioned with regard to the definitions of direct and indirect discrimination, the comparability of the less favourable or disadvantageous treatment must occur in respect of (an)other person(s). The question that immediately comes to mind is: who are these other persons? Who can be used as a point of comparison for the enforcement of such rules? Even though the Directive is not explicit, the jurisprudence establishes a number of guidelines for those interpreting it. In a major ruling

12 In any event, it is worth noting that the comparator approach has been criticised. Mark Bell \& Ann Numhauser-Henning (n 6), 155: 'this tends to reinforce the norms and conduct of dominant groups who become the benchmark against which treatment is compared. The comparator, whether real or hypothetical, is likely to have characteristics such as being white, abled-bodied or a man'.

13 As Catherine Barnard, EU Employment Law, 4" ed., Cambridge, Cambridge University Press, 2012, 305, argues, 'in most cases the selection of the comparator is straightforward. However, this is not always the case'. On the other hand, Mark Bell \& Ann Numhauser-Henning (n 6), 154, point out: 'in some cases, the Court appears to place less weight on the identification of a comparator'.

14 Case $V L$, Opinion of $A G$ Pitruzzella, para 36. 
involving discrimination due to sexual orientation, the Court of Justice stressed that 'first, it is required not that the situations be identical, but only that they be comparable and, second, the assessment of that comparability must be carried out not in a global and abstract manner, but in a specific and concrete manner in the light of the benefit concerned'. ${ }^{15}$

If the premise here is that the nature of these situations is only comparative, then it seems that, $a$ fortiori, the maximum equalisation among them also falls within the Directive's normative approach. Would it make sense to remove a case from the Directive's protective scope, where an employer enforces a measure that benefits employees with physical disabilities but not a group of employees with mental disabilities, if it were conceded that such measure could also benefit the latter? Would this not be favourable treatment of a certain group of workers with disabilities to the detriment of another group of workers with disabilities? An affirmative answer to the first question - that is, to admit differentiation in these types of situations, as the interpretation by the Commission and the hospital seems to infer, unless a better opinion is put forward - reflects a formal interpretation of the Directive and is contrary to its scope, which, I reiterate, is to combat discrimination.

In the $V L$ case, the CJEU not only recalled that in interpreting a provision of EU law it is necessary to consider not only its wording but also its context and the objectives of the legislation of which it forms part, ${ }^{16}$ but also emphasised that the wording of Article 2(1) and (2) of the Directive, in particular, the terms 'another [person] and other persons', 'does not permit the conclusion that, regarding the protected ground of disability [...], the prohibition of discrimination laid down by that directive is limited only to differences in treatment between persons who have disabilities and persons who do not have disabilities'. ${ }^{17}$

The protection granted by that Directive, added the Court, "would be diminished if it were to be considered that a situation where such discrimination occurs within a group of persons, all of whom have disabilities, is, by definition, not covered by the prohibition of discrimination laid down thereby solely on the ground that the difference in treatment at issue takes place as between persons with disabilities'. ${ }^{18}$

At the end of the day, if the Court of Justice conceded on the position of some of the parties in the process, including that the Directive only encompasses differentiated treatment among workers with a disability and workers with no disability, 'such an interpretation could result in the paradox of reverse discrimination, which would impose on employers an absolute and automatic obligation to treat all disabled workers equally'. ${ }^{19}$ Within a company where there is a group of disabled workers, each one of them can request that reasonable accommodations be put in place, and, in this case, the employer must treat them differently.

15 CJEU Case C-147/08 Jürgen Römer v Freie und Hansestadt Hamburg [2011] ECLI:EU:C:2011:286, para 42.

16 Case $V L$, para 26. See also the Opinion of AG Pitruzzella, para 38.

17 Case VL, para 29. At para 30, the Court added: 'although Article 1 and Article 3(4) of that directive, as well as recitals 11 and 12 thereof, make generic references to discrimination "on the grounds of" or "based on", inter alia, disability, they do not specify in any way the person or group of persons that may be used as the benchmark for assessing whether there is such discrimination'.

18 Case $V L$, para 35.

19 In this sense, see Case $V L$, Opinion of AG Pitruzzella, para 44. 


\section{Direct or indirect discrimination?}

Even more debatable is the Court of Justice's argumentative rhetoric with regard to qualifying the hospital's discriminatory conduct as direct or indirect. On the one hand, and knowing that the Court of Justice presented such conclusions to the national judicial authorities, it is also true that its projection was not based on the logic of such discriminatory-type cases. As is clear, as well as the fact that they alternate, the latter derives from the former - in other words, when the scope of points (a) and (b) of Article 2(2) of Directive 2000/78 are outlined, assessing the type of indirect discrimination generally only takes place once the direct discrimination has been dismissed. Nevertheless, in the case in question, the Court of Justice stated that the hospital's behaviour could be considered not only direct discrimination, but also indirect discrimination.

But perhaps the most sensitive point of the decision relates to the possible subsumption of the $V L$ case in the desideratum regarding direct discrimination (Article 2, no. 2, a)). So, the question we ask ourselves is whether worker, VL, was in fact treated less favourably due to her disability.

In light of the case law concerning grounds other than disability referred to in Article 1 of that Directive, the Court has held that a 'difference in treatment based on workers' marital status and not expressly on their sexual orientation was still direct discrimination on the basis of that orientation because, in the Member States concerned, at the time of the facts under consideration, only persons of different sexes could marry and it was therefore impossible for homosexual workers to satisfy the condition necessary for obtaining the benefit claimed. In such a situation, marital status could not be regarded as an apparently neutral criterion'. ${ }^{20}$

In the same vein, the Court recalled that 'a difference in treatment of workers based on entitlement to an old-age pension and not expressly on age, in granting a severance allowance, constituted direct discrimination in so far as, that entitlement being subject to a minimum age requirement, that difference in treatment was based on a criterion which was inextricably linked to age'. ${ }^{21}$ Therefore, the Court concluded: 'where an employer treats a worker less favourably than another of his or her workers is, has been or would be treated in a comparable situation and where it is established, having regard to all the relevant circumstances of the case, that that unfavourable treatment is based on the former worker's disability, inasmuch as it is based on a criterion which is inextricably linked to that disability, such treatment is contrary to the prohibition of direct discrimination'. ${ }^{22}$

With regard to this matter, it should be noted that the Court of Justice shunned both the Court's interpellation by the Court of Appeal, which referred solely to the indirect discrimination (that there was difference in treatment based on an apparently neutral criterion, namely, the date on which the disability certificate was delivered), and the understanding by the Advocate General.

We cannot, however, perceive a direct similiarity between the adduced case-by-case and the case hereby presented. In truth, there is a particularly relevant factor that distinguishes and sets them apart: whilst in the examples there are differences in how heterogenous groups of people (married and unmarried/older and younger workers) are treated, the question at hand in the $V L$ case concerned differentiated treatment of a group of people who all have the same protected characteristic (they are disabled). Furthermore, in the former, the criteria used to determine discrimination were marriage and age, whereas in the $V L$ case the difference in treatment was based on the date the worker delivered her disability certificate to the hospital.

\footnotetext{
20 Case $V L$, para 45.

21 Case $V L$, para 46.

22 Case $V L$, para 48.
} 
It is important to note, however, that what has been described does not mean that less favourable treatment of a disabled worker in comparison to another disabled worker can constitute direct discrimination when such difference in treatment is based on that characteristic. In the $V L$ case, I would unequivocally consider it to be a case of direct discrimination under the terms of Article 2, no. 2, a), of Directive 2000/78 if the grounds for the different treatment of VL had in actual fact related to her disability. In other words, if the differentiating measure issued by the hospital had targeted such characteristic, and had explicitly referred to it, it would constitute direct discrimination.

As I see it, and not considering the element of time - that is, the date on which the disability certificate was delivered - to be directly related to the protected characteristic (VL's disability), the hospital's discriminatory conduct constitutes indirect discrimination (Article 2, no. 2, b) of Directive 2000/78) inasmuch as it derives from an apparently neutral criterion which, nevertheless, leads to a particular disadvantage for workers with a disability, including VL. ${ }^{23}$ Such discriminatory treatment cannot be objectively justified in compliance with the said norm as it is based on the hospital's aim to reduce monetary costs. ${ }^{24}$

\section{Conclusion}

Considering the above, I believe that under Directive 2000/78, the Court of Justice was right in admitting that the situations in which a homogenous group of workers with a common characteristic - in this case, a disability - were comparable. However, the same cannot be said for the possible subsumption of this controversial case in the definition of direct discrimination. As I see it, the Court of Justice should have adopted the Advocate General's interpretation, considering the hospital's behaviour solely as indirect discrimination - unless, for some reason, the aim here was to widen the scope of the material protection under Directive 2000/78. Perhaps the Court of Justice can clarify this matter in the future.

\section{Declaration of conflicting interests}

The author(s) declared no potential conflicts of interest with respect to the research, authorship, and/or publication of this article.

\section{Funding}

The author(s) disclosed receipt of the following financial support for the research, authorship, and/or publication of this article: This work was supported by the Portuguese Foundation for Science and Technology (grant number SFRH/BD/146029/2019).

\section{ORCID iD}

Pedro Oliveira (iD https://orcid.org/0000-0002-0370-0788 